\title{
Dicotomías narrativas en "El árbol" de María Luisa Bombal
}

Paola Bianco

Wilkes University

L

a obra narrativa de María Luisa Bombal refleja la condición de la mujer hispana a través de la textualización del contexto social e histórico de una época en que la conducta y los rasgos psicológicos de cada sexo estaban claramente definidos ${ }^{1}$.

Esta división de papeles ha dado lugar a un sistema de dicotomías que atribuyen al hombre, como señala Guerra-Cunningham, las características innatas de vigor y habilidad intelectual, mientras que a la mujer le corresponden las de un individuo pasivo, dócil e intuitivo (32). Los comentarios de GuerraCunningham son un eco de la tradicional dicotomía antropológica entre mujer-naturaleza y hombre-cultura, correspondiendo el último binomio al orden falocéntrico que dicta las normas del patriarcado.

En toda la obra de Bombal existe una constante presencia de la naturaleza que le sirve como expresión simbólica de los estados más íntimos de sus protagonistas femeninos y de su situación marginal.

En "El árbol” (1939) la naturaleza se convierte en el refugio de una protagonista que experimenta la represión bajo las reglas del patriarcado, y este refugio lo encuentra en el cuarto de vestir, "in the freshness of the dressing chamber, poetically presented in cool and aquatic imagery" (Bente, 110) y en el gomero. La docilidad y pasividad de Brígida, protagonista del cuento, transparentan las relaciones de género en una época histórica en la que la mujer se sentía marginada en todos los órdenes de su vida, tanto pública como privada. En el contexto histórico del Chile de los años 30, donde se desarrolla la trama del cuento, se puede observar que la conciencia de Brígida sufre las limitacio-

${ }^{1}$ K. M. Sibbald e Ilse Adriana Luraschi subrayan que no se sabe si la autora chilena era consciente de la ideología feminista que se percibe en sus obras, y hasta qué punto estaba dispuesta, como muchas de sus coetáneas, a una toma de conciencia sobre el problema de la desigualdad social basada en el sexismo (Apreciaciones críticas, 237). 
nes que le impone el patriarcado desde fuera; y la autorrepresión que siente se convierte en una opresión internalizada ${ }^{2}$. Es en el momento en que la alienación de los mundos exterior e interior coinciden cuando Brígida toma la firme decisión de abandonar a su esposo, y así se libera de su condición sofocante de mujer marginada.

"El árbol" textualiza una representación paradigmática de la sociedad patriarcal en la que el matrimonio era para la mujer la meta prioritaria. La diégesis narrativa del cuento se estructura en base a un planteamiento dicotómico que coincide con las reglas definidas por el sistema patriarcal. El término patriarcado tiene una larga tradición histórica, y hoy día se utiliza en la crítica feminista para designar la opresión que sufre la mujer bajo el poder de la autoridad masculina. Adrienne Rich señala:

Patriarchy is the power of the fathers: a familiar -social, ideological, political- system in which men by force, direct pressure or through ritual, tradition, law, and language, customs, etiquette, education, and the division of labor, determine what part women shall or shall not play, and in wich the female is everywhere subsumed under the male... Under the patriarchy... I live under the power of fathers, and I have access only to so much of privilege or influence as the patriarchy is willing to accede to me, and only for so long as I will pay the price for male approval (57-8).

Asimismo, Kate Millet señala que nuestra sociedad, como cualquier otra civilización histórica, se funda en un patriarcado, y este hecho se evidencia en todos los órdenes de la sociedad: industria, universidad, ciencias, etc.: "Every avenue of power within the society, including the coercive force of the police, is entirely in male hands" (25).

En la narración de la historia del cuento, la voz narrativa rompe con el desarrollo cronológico lineal y viola las leyes de causalidad que dominan en la narración tradicional realista; y esta fragmentación en la estructura del relato refleja a nivel externo la división de géneros en la sociedad, la alienación familiar y social que sufre la protagonista, y su desequilibrio emocional. "El árbol" se presenta como una evocación memorística enmarcada en el espacio de la imaginación de Brígida, y en él se decribe la soledad, dependencia y falta de

${ }^{2}$ Los orígenes del patriarcado se encuentran en Friedrich Engels. En su obra The origin of the Family, Private Property and the State Engels estudia los medios de apropiación y señala que las mujeres perdieron poder al darse prioridad a los medios de producción -comida, artículos de lujo, etc.- sobre los de reproducción de la especie. La producción generó un excedente de bienes para el intercambio comercial en lugar de su consumo directo. De esta forma, aquellos que poseían tales excedentes trataban de dejarlos en herencia a herederos legítimos, y se aseguraban de ello mediante la imposición del matrimonio monógamo (Stacey, 54-5). 
comunicación que siente Brígida en su relación matrimonial con Luis, un hombre mucho mayor que ella y que no satisface los deseos de procreación de su esposa $^{3}$. Explica Marjorie Agosín que "la heroína bombaliana comienza viviendo en un estado armónico con la naturaleza, pero poco a poco es aislada de esta atmósfera inicial y es obligada a refugiarse en la imaginación" (162). La frustración de Brígida se manifiesta por medio de un encadenamiento de fantasías que se suceden mientras asiste a un concierto de música clásica, y una vez asumida y comprendida su condición de mujer alienada se libera del yugo patriarcal. A nivel paradigmático, por tanto, el cuento narrativiza la opresión de la mujer bajo el sistema partriarcal y su liberación final. Mackinnon explica que "male and female are created through erotization of dominance and submission" (635), y esta dinámica define la relación hombre y mujer dentro del sistema patriarcal. Al casarse con Luis, Brígida participa de las normas impuestas por el sistema patriarcal, y su aislamiento subsiguiente no supone una paradoja dialéctica, sino la única solución posible en un contexto social dominado por el hombre.

En el matrimonio de Brígida y Luis se delinean nítidamente los roles de cada sexo en el contexto de una sociedad patriarcal. Luis, por una parte, "cumple con su papel masculino a la perfección y como las leyes de la sociedad lo defienden y apoyan en todas sus acciones, no le pasa por la mente el deseo de cambiar" (Gálvez Lira, 31) o de satisfacer a su esposa. Y Brígida, por otra, huérfana de madre y la más joven de seis hijas ${ }^{4}$, es relegada desde niña a un

${ }^{3}$ Algunos estudios han analizado la simbología, el lirismo, la estructura narrativa, el análisis del lenguaje y la condición de la existencia femenina en "El árbol", pero solamente un número reducido de artículos ha dado importancia a la falta de fertilidad de la pareja. Es preciso tomar en cuenta este factor que es esencial para entender cómo el ambiente sociológico y cultural de ese período histórico influye sicológicamente en Brígida. No se puede determinar si la culpa es del marido. Sin embargo, a través del cuento hay indicaciones que apuntan hacia Luis. Thomas O. Bente menciona:

Contrary to the unnamed heroine of La uiltima niebla and Ana María in La amortajada, Brígida is neither as psychotic as the former nor as artful and vindictive as the latter; she shares with them, however, the same sexual-emotional frustration of her marriage. In this case, one is inclined to attribute the sterility of their marriage to Luis; there is not the slightest evidence of tenderness of physical interest on his part (110).

Asimismo, Cárdenas señala que "cuando Luis rechazó el amor carnal de Brígida, ésta buscó una manera de salir de sus sufrimientos físicos" (56).

${ }^{4} E s$ necesario aclarar que en este período histórico y social era importante para la familia que el primogénito fuera varón porque aportaba al patrimonio familiar. Las mujeres, en cambio, necesitaban la dote para casarse y no contribuían dinero porque no trabajaban fuera de la casa. 
segundo plano por un padre que cuando llegó "por fin a su sexta hija, llegaba tan perplejo y agotado... que prefería simplificarse el día declárandola retardada" (343). Además, en lugar de preocuparse por la educación de su hija, el padre la ignora afirmando que "si le gustan las muñecas a los dieciséis años, que juegue" (343). El ambiente familiar y el contexto social de la época han modelado de tal modo las expectativas de Brígida que su principal objetivo consistía en casarse y ser madre, único modo de poder llegar a ser aceptada y sentirse realizada en su ambiente social, de ahí su preocupación cuando veía que "una por una iban pidiendo en matrimonio a sus hermanas. A ella no la pedía nadie" (344) . A falta de otras opciones, Brígida termina por convertirse en la esposa de Luis, íntimo amigo de su padre. El matrimonio, eventualmente, llegará a ser el mundo del que tratará de evadirse, y éste es el punto de partida de una dicotomía fundamental y dominante en la vida de la protagonista: la influencia opresora del mundo exterior y los deseos de liberación que se van gestando en su conciencia.

El matrimonio, según Pratt, es un "archetypal enclosure", "one of the primary tools for dulling a hero's initiative and restraining her maturation" (41), y en un gran número de novelas centradas en la relación matrimonial de los protagonistas, la tensión entre los deseos de la protagonista y los dictados impuestos por la sociedad dan lugar a unos patrones arquetípicos de persecución y sumisión, acompañados por imágenes de sofoco, empequeñecimiento y enfermedad mental (Pratt, 41-2). Mary Daly añade que la separación de la casa de los padres va seguida, tras el matrimonio de la mujer, de un regreso a la dominación paternalista en el hogar del esposo y, así, "the eternal cycle of separation from and return to infantile dependence has been the story of the feminine existence" (24-5). Con la salida de Brígida del hogar familiar, y con su entrada en la institución del matrimonio, "El árbol" inscribe el mito de separación de y regreso a un sistema falocéntrico, y plantea, asimismo, la búsqueda de una subjetividad femenina al margen de este orden patriarcal. Lo mismo que el padre de Brígida, Luis tampoco le da a su esposa la atención necesaria, y antepone sus obligaciones profesionales a las de esposo: "soy un hombre muy ocu-

${ }^{5}$ En sus estudios sociológicos, basados en encuestas y entrevistas, Michelle y Armand Matterlat han demostrado que para que la mujer se sienta social y culturalmente satisfecha dentro de la mentalidad de este período, debe llegar a ser esposa y madre. Algunos de los comentarios de estas mujeres entrevistadas incluyen: "considero que el matrimonio es una experiencia necesaria que si no se realiza, provoca frustraciones en la mujer, una vez llegada ésta a cierta edad", "la mujer debe pasar por el matrimonio y la maternidad para alcanzar el pleno desenvolvimiento de su naturaleza y de su personalidad", "no está completa su vida porque la vida de una mujer se completa con los hijos", "la mujer debe ser madre y esposa y cooperar así con la sociedad" (99). 
pado. Se llega a mi edad hecho un esclavo de mil compromisos" (348). El sistema patriarcal, como es sabido, relega a la mujer a la esfera doméstica del hogar, marginándola de la vida pública e intelectual. El único trabajo de Brígida queda circunscrito al desempeño de las labores del hogar ${ }^{6}$. Privada de descendencia, no se siente internamente realizada como mujer, ni cumple, externamente, con la función reproductora que la sociedad patriarcal asigna a la esposa ${ }^{7}$. Atrapada en un mundo sin comunicación en el que no puede expresar sus deseos y sentimientos, Brígida escapa de esta realidad a través del ensueño de viajes imaginarios. Joseph Sandler explica con respecto a las fantasías de la imaginación:

The creation of conscious daydreams is a major form of wish-fulfilment available to us during waking life, in the absence of gratification, satisfaction or fulfilment arising from the external world... Freud saw the daydream as a wish-fulfilling product of the imagination $(34)^{8}$.

El planteamiento dicotómico del cuento sigue la división tradicional de mujer / hombre como representación de la dualidad desorden / orden, materia / espíritu, o sinrazón / razón. Según Plumwood, el desarrollo de algunos dualismos, como razón/naturaleza son ancestrales, pero otros, como humano I naturaleza o sujeto/objeto, se asocian con una conciencia moderna y postneoclásica (43), pero en los últimos años esta división ha sido rebatida por el nuevo feminismo como una apreciación patriarcal claramente disfuncional.

${ }^{6}$ Michelle y Armand Mattelart indican que la percepción tan rígida de los roles del hombre y de la mujer en el hogar origina entre los hombres de todas las categorías una alta proporción de respuestas negativas al trabajo fuera del hogar de la mujer casada. Incontestablemente para la mentalidad masculina, el rol primordial de la mujer casada es el de dueña de casa y madre de familia (115).

Asimismo, Guerra-Cunningham observa que la mujer durante siglos ha estado condenada a la dependencia económica y la vida aislada en el hogar (21).

${ }^{7}$ Varias teorías han tratado de explicar desde distintos puntos de vista -sociológico, político, o sicológico- las razones de la marginación de la mujer y la asimetría entre ésta y el hombre. Siempre, en la historia de las civilizaciones, el papel primordial de la mujer ha sido el de tener hijos. Esto se asocia a la función biológica que tiene cada sexo, y que a su vez causa la diferencia entre los dos sexos. La reproducción es de importancia vital, y es esencial para satisfacer la función biológica, social y sicológica de la mujer. Shulamith Firestone, en The Dialectic of Sex, comenta: "Let us first try to develop an analysis in which biology itself -procreation- is at the origin of the dualism" (6) y afirma que "a basic mother/child interdependency has existed in some form in every society, past or present, and thus has shaped the psychology of every mature female and infant" (9).

${ }^{8}$ Es difícil establecer si María Luisa Bombal estaba al corriente de la teoría sicoanalítica de Freud. La evasión de la realidad insatisfecha a través de los ensueños es ilustrada en todo el cuento por medio de las fantasías de Brígida durante el concierto. 
La estructura dicotómica del cuento polariza las fuerzas narrativas en dos frentes antagónicos, jerarquizados y diferenciados, y la barra que delimita estos dos mundos constituye una frontera que separa dos mundos irreconciliables. Luis representa la parte dominante en la estructura dual del pensamiento occidental que, como indica Plumwood, "construes and constructs difference in terms of an inferior and alien realm" (42), y a Brígida le corresponde el papel de subordinada dentro de este sistema de diferencias.

Los distintos planos narrativos de "El árbol" se estructuran en base a una coherente dualidad espacio-temporal en la que la narración se mueve del presente de la sala de conciertos al ámbito asfixiante del hogar y a la relación matrimonial de la protagonista. Realidad actual y pasado imaginado son, por tanto, los polos sobre los que gravita la narración de la historia, y a través de esta dualidad la voz narrativa articula dos aspectos antágonicos en la vida de Brígida: liberación de y entrada en la clausura represora del matrimonio. Aunque el relato está narrado en tercera persona, la voz narrativa lo focaliza internamente, primando la perspectiva de la protagonista. Por ello, y como indica Debicki, a pesar de que la voz narrativa es en tercera persona, "the focus is so much on Brígida that the work has the same of the effect of a first person narrative" (124). Toda la narración se construye desde el presente de la sala de conciertos por medio de analepsis y prolepsis, técnicas que, en efecto, le complican al lector la trama de "armar" la tarea de una vida fragmentada ${ }^{9}$. La evocación del pasado, producto de la fantasía creadora de su imaginación, es continuamente interrumpida por un presente que "la deja en una sala de conciertos, vestida de negro, aplaudiendo maquinalmente" (344). Aunque su esposo no ha muerto, el luto de Brígida proyecta a nivel connotativo la muerte simbólica de la relación matrimonial. No faltan tampoco, dentro de la rememoración del pasado, ejemplos de prolepsis que anticipan y retrotraen el desarrollo de la acción a un tiempo presente más cercano: "Brígida, ayer encontré a tu marido, a tu ex-marido, quiero decir" (343). La analepsis, o visión retrospectiva, sirve para la recreación de un pasado de Brígida que va de la infancia al momento presente, pasando por las distintas etapas de juventud y experiencia matrimonial. De este modo, se postula una inscripción epistemológica de las dicotomías occidentales centrada en la oposición entre cultura/naturaleza y espacio público/privado, que ha perpetuado la opresión de la mujer occidental. Y los protagonistas del cuento, Brígida y Luis, encarnan esta oposición metafísica y dialéctica ${ }^{10}$.

${ }^{9}$ Para un estudio pormenorizado de la analepsis y prolepsis consúltese el estudio de Gérard Genette, Narrative Discourse (39-40).

${ }^{10}$ Para un estudio de la dicotomía espacio privado/público en la historia occidental, comenzando con Grecia, consúltese el estudio de Carol Bigwood (130-36). 
Hall explica que la naturaleza, representación metafórica de la selva virgen, es el lugar fértil que ha fructificado gracias a sus condiciones naturales, que toma la vida en sus manos, que se apropia de los residuos o restos y los recicla, y que es virgen porque no ha sido aún explotada por la mano del hombre (11). La identificación del cuerpo humano con el de la naturaleza nos da, según Frye, el arquetipo de imágenes arcádicas, el "green world", y este mundo arcádico presenta algunas analogías no sólo con el mundo fértil del ritual, sino también con el mundo de los sueños que creamos con nuestros deseos $(183,144)$. A través del arquetipo del "green world", la mujer, y en nuestro caso Brígida, puede expresar su yo y manifestar su verdadera autenticidad ${ }^{11}$. Dölz-Blackburn explica que María Luisa Bombal usa la naturaleza en toda su obra para transmitir varios mensajes y que, en última instancia, ésta le sirve como acto de liberación final (56) ${ }^{12}$. En La última niebla, por ejemplo, la protagonista "desnuda y dorada, se sumerje [sic] en el estanque" (14), y al sumergirse desnuda se libera, como Brígida, de la opresión sofocante del patriarcado y se autodefine a sí misma como mujer.

${ }^{11}$ Oscar Fernández subraya que "en la mitología las asociaciones entre los dioses y los árboles eran múltiples, por ejemplo, Júpiter y la encina, Osiris y el cedro y Apolo y el laurel" (352). La narración mitológica de Apolo y Dafne, que forma el arquetipo "trauma de la violación”, recurre en literatura como una de las estructuras argumentales más frecuentes en la ficción escrita por mujeres. Según el mito, la ninfa Dafne se convierte en laurel para resistir los acosos eróticos de Apolo, y al metamorfosearse en un laurel evita ser violada por Apolo (Pratt 4-5).

${ }^{12} Y a$ se ha notado que la naturaleza adquiere múltiples significados y funciones: refugio, protección, o liberación. En otros cuentos o novelas de Bombal, la naturaleza se convierte en una extensión o distorsión de la mujer misma: "Las verdes enredaderas que se enroscan a los árboles, las dulces algas a sus rocas, son cabelleras desmadejadas, ..." ("Trenzas" 64); "Pero, nacidas de su cuerpo, sentía una infinidad de raíces hundirse y esparcirse..." (La amortajada 162); Brígida "era como una planta encerrada y sedienta que alarga sus ramas en busca de un clima propicio" ("El árbol” 345); "no me sabía tan blanca y tan hermosa. El agua alarga mis formas, que toman proporciones irreales" (La última niebla 14), o sirve para reafirmar la esencia femenina: "Nunca me atreví antes a mirar mis senos; ahora los miro. Pequeños y redondos, parecen diminutas corolas suspendidas sobre el agua" (La última niebla 14). Con respecto a la naturaleza, Borinsky subraya que Yolanda, protagonista de "Las islas nuevas", se puede ligar a la naturaleza: "El término que une el nombre de Yolanda a su cuerpo está dado en la forma de una hipótesis que la liga a la naturaleza" (32). Yolanda "es igual que su nombre: pálida, aguda y un poco salvaje..." (72). Borinsky hace un paralelismo entre el nombre y la protagonista de "Las islas nuevas", "Yolanda idéntica a su nombre, tiene una identidad más allá o más acá de la humanidad, un nombre que la acerca al salvajismo, a una naturaleza aún no conquistada" (32), a una naturaleza virgen y en su estado primitivo. Brígida es la naturaleza en su estado primitivo, "en el sentido de no haber sido educada. Su marido, Luis, le explica que se ha casado con ella por 'sus ojos de venadito asustado"'(33). El paralelismo entre las protagonistas y el mundo vegetal/naturaleza es evidente. 
La naturaleza es un componente temático clave en cada una de las tres partes en que se divide el cuento. Para dar unidad a la dislocación del orden cronológico, la autora se sirve de tres elementos claves: las estaciones del año, la música y la naturaleza. La descripción, que según Hamon representa la conciencia lexicográfica del enunciado (45), cobra una gran importancia en este relato, y a través de ella la voz narrativa expresa los sentimientos más íntimos de Brígida. La música tiene una función polivalente en la narración, y la narradora la emplea no solamente para marcar una división en las tres etapas de la vida de Brígida, sino también para darle un tono de lirismo que se revela con notas románticas y nostálgicas, dotando al cuento de una exquisita musicalidad. El calendario, por otro lado, cobra una función primordial al marcar el paso inexorable del tiempo en la vida de Brígida: "Llegó el verano, su primer verano de casada" (348) y "vino el otoño" (352). Al contextualizar el relato en el marco temporal de las estaciones, y de un un tiempo cíclico, la narradora pone de relieve el carácter repetitivo al que se ve sujeto la dinámica matrimonial de Brígida y su condición de mujer marginada.

Más importante, no obstante, que estos dos elementos narrativos es el que Bombal atribuye a la naturaleza. Aunque el concierto dura aproximadamente dos horas, en este lapso, y simultáneamente, la protagonista ve transcurrir algunos de los momentos más significativos de su vida. Las tres sonatas del concierto, de Mozart, Beethoven y Chopin, acompañan a Brígida en sus viajes imaginarios de férvida fantasía, y reflejan simbólica y metafóricamente las distintas etapas de la vida de Brígida y los correspondientes estados emocionales por los que pasa su conciencia de mujer alienada. La música de Mozart lleva a una joven Brígida de dieciocho años, vestida de blanco, por un jardín con un puente sobre agua pura y arena rosada, y, según Seymour, Menton, esta música de Mozart acompaña a la niñez despreocupada de Brígida (354). La evocación inicial del motivo del jardín es importante porque une el principio con el final de la vida de Brígida. Por un lado, el jardín representa simbólicamente la inocencia de la protagonista, "el jardín de los años juveniles" (343) y, por otro, en el comentario de una amistad de Brígida relativo al final de su relación matrimonial con Luis, se insinúa el nacimiento de la protagonista a una nueva vida liberada de su esposo. El segundo compositor es Beethoven, y a través de sus notas románticas se revela la frustración de Brígida como mujer casada. Si la sonata de Mozart se ubica en la primavera, la sinfonía de Beethoven sitúa los recuerdos de Brígida en el calor asfixiante y agobiante del verano. En lugar del jardín, la emergencia del yo, del self, de Brígida se inscribe por medio de dos símbolos polisémicos: el mar y el gomero. Según Scott, “... Beethoven initially enfolds her in the sensual rythms of the sea, which first pushes her into Luis's embrace and then recedes and abandons her" (5). La fuerza arrastradora del 
mar que envuelve con sus olas a Brígida para retirarse y dejarla "olvidada sobre el pecho de Luis" (345), representa las ilusiones truncadas que Brígida depositó en el amor de su esposo. El gomero, por su parte, representa la proyección simbólica de su subconsciente, el último refugio o reducto en el que la solitaria Brígida encuentra consuelo ${ }^{13}$. Nor Hall apunta que "weaving a cocoon out of the substance of one's own life is the necessary prerequisite for the emergence of psyche: in withdrawing we prepare a way out. Any of the feminine types on the structural poles can go through this experience of withdrawal in service of the emergence of self" (147-48). En una tercera etapa, la música melancólica y triste de Chopin le hace entender su situación de esposa sin hijos en un mundo vacío y sin vida ${ }^{14}$.

$\mathrm{Al}$ incumplimiento de las promesas de Luis, como la de llevar a Brígida a Europa para que viera nevar (347), se une su total indiferencia para acentuar aún más una soledad y marginalización de Brígida iniciadas primeramente en el hogar familiar de sus padres. Brígida se da cuenta de que no ama a Luis y de que éste tampoco la ama, y al llegar a este punto de reflexión cognoscitiva, del cumplimiento, según Jung, de un proceso de individuación, se produce un renacimiento de la protagonista a una nueva vida y toma la decisión de abandonar a Luis. Brígida vive y representa la percepción que el sistema patriarcal tiene de ella, y para salir de este orden debe superar un proceso de individualización que la lleva a través de varias etapas. Debe evitar la mirada en el espejo falocéntrico, reconocer sus problemas, y acto seguido logrará emerger renovada como un ser independiente.

En su relación matrimonial con Luis, Brígida ha intentado comunicarse siguiendo varias tácticas: ya sea reprochándole su falta de amor y atención, ya sea aceptando la indiferencia del marido, quien "nunca la escuchaba del todo. Le sonreía con una sonrisa que ella sabía maquinal" (347) y, finalmente, a través del silencio:

- ¿Quieres que salgamos esta noche, Brígida?

..- .

-¡Qué lindo traje! ¿Es nuevo?

- ...

-¿Es nuevo, Brígida? Contesta, contéstame. . .

Pero ella tampoco esta vez quebró el silencio.

${ }^{13}$ Contrariamente, Gwendolyn Díaz interpreta el gomero como una representación fálica que sugiere la falta de amor y pasión de Luis: "once more we find the tree and light..." (58).

${ }^{14}$ Según Parra, la música de Chopin le evoca la tristeza de un amor frustrado y la frialdad de su marido (168). 
Y en seguida lo inesperado, lo asombroso, lo absurdo. Luis se levanta de su asiento, tira violentamente la servilleta sobre la mesa y se va de la casa dando portazos (349).

Aunque en esta instancia narrativa se interrumpe la comunicación, Brígida utiliza el silencio para sacar a Luis de su indiferencia, para provocar una reacción emocional en él, para rebelarse y ocupar una posición de poder y control. Por primera vez, Brígida provoca un efecto emocional en el comportamiento del marido al no saber éste cómo controlar su cólera, y a través del silencio de Brígida nos da a entender que Luis pierde temporalmente el control y autoridad sobre su esposa ${ }^{15}$.

Ya que no tiene a nadie con quien hablar, Brígida recibe consuelo del gomero. En sus momentos de desolación e incomprensión, Brígida se retira al cuarto de vestir donde el gomero, delante de la ventana, filtra la luz. Y es aquí, en la penumbra del cuarto, donde ella se refugia para oír el suave ruido monótono de la lluvia y contemplar "su gomero". Esta escena, descrita repetidamente, nos presenta el papel apaciguador del gomero. En los momentos de hastío y soledad, el mundo natural del gomero ofrece a Brígida la serenidad, comprensión y comunicación que no le brinda su esposo. Magali Fernández comenta que "para la existencia solitaria de la heroína, el árbol se ha transformado en un elemento personificado, en el único ser con quien logra comunicarse" (58). Irónicamente, todas las connotaciones simbólicas que vinculan al árbol con la fecundidad y la reproducción son precisamente las que faltan en la vida de Brígida. La imagen que se desprende del árbol, repleto de pájaros, es una proyección simbólica de los deseos maternales de Brígida. Además de servirle como refugio, consuelo y proyección de su subjetividad femenina, el gomero tiene una doble función. Si, por un lado, el ramaje del árbol le priva a Brígida de una visión completa de la calle, de un conocimiento de la realidad exterior, por otro le sirve para llegar a una comprensión de su interioridad y a la resolución definitiva de terminar su relación matrimonial. Una vez que cortan el gomero, el cuarto se llena de una "luz blanca aterradora. . . Y todo lo veía a la luz de esa fría luz; Luis, su cara arrugada. . .” (353). Brígida, ahora, percibe la realidad del mundo exterior: una calle estrecha, un rascacielos deslumbrante, muchachos que patean una pelota en medio de la calzada, trapos colgados, la vejez del marido, y siente que esta realidad infringe la privacidad de su retiro alienante. Una vez abatido el árbol, el cuarto lleno de luz le había:

${ }^{15}$ Para mayor información sobre el silencio véase el artículo de Emma SepúlvedaPulvirenti. 
quitado su intimidad, su secreto; se encontraba desnuda en medio de la calle, desnuda junto a un marido viejo que le volvía la espalda para dormir, que no le había dado hijos (353).

Con la caída del árbol, llega el momento climático del cuento. A raíz de esta experiencia, la vida de Brígida experimenta un giro decisivo, un punto de inflexión en el que ella se ve desnuda, sin la máscara que tiene que mantener frente a la sociedad patriarcal, se enfrenta a su propia existencia, y decide vivir una vida de independencia plena sin Luis. La irrupción de las raíces del árbol en la acera, su exteriorización, representa el final de la clausura de Brígida en el refugio de su salón de vestir, es el momento en el que ella ha sacado a la luz los problemas latentes en su subconsciente y se enfrenta a la realidad de su vida con Luis. La presencia de la luz en la oscuridad de su alienación le hace posible comprender y enfrentarse a la realidad de su frustrado matrimonio y abandonar el retiro de sus ensueños y fantasías. La tala del gomero coincide con el final del concierto y con el retiro de Brígida en el mundo de sus fantasías para, a partir de ahora, enfrentarse a una nueva realidad. Como indica Gálvez-Lira, apenas termina el concierto "la sala de conciertos se ilumina bruscamente. Es el final del mismo, final que coincide con el derrumbamiento del árbol, es decir, el término de su mundo de ensueños y enfrentamiento con la realidad" (25).

La entrada de la luz en su cuarto corresponde con la luz que invade la sala de conciertos al final del cuento. Esta luz, en ambos planos narrativos, apunta a un mismo fin: la comprensión por parte de Brígida de su enajenación, la irrupción de la realidad exterior en su vida y la iniciación de una vida independiente, fuera de la clausura del salón de vestir y liberada de la opresión patriarcal. El cuento concluye con la firme decisión de Brígida de abandonar a Luis: “-Mentira! Eran mentiras su resignación y su serenidad; quería amor, sí amor, viajes y locuras, y amor, amor" (354). La razón que da al marido cuando le pregunta por qué se va es, simplemente: "-¡El árbol, Luis, el árbol! Han derribado el gomero" (353).

María Luisa Bombal revela en este cuento cómo el sistema patriarcal ignora la subjetividad femenina, y cómo ésta logra expresión en el retiro alienante de la naturaleza. Para acentuar la dicotomía entre la vida actual insatisfecha y el ensueño que representan los anhelos y las ilusiones reprimidas, María Luisa Bombal juega con el tiempo, el espacio y, al final del cuento, con la sombra y la luz, para crear una cierta tensión que se mantiene a través de toda la narración, y para marcar el tránsito de una existencia opresiva a una nueva realidad liberada del yugo patriarcal. No obstante lo cual, la introspección de Brígida, o la tejedura de un capullo, como indica Nor Hall, le dapara una salida liberadora 
del orden patriarcal y la emergencia de un nuevo self. La evocación ensoñadora del pasado de Brígida se circunscribe al ámbito de la memoria, al silencio del recuerdo, carece de voz o escritura porque éstas han sido silenciadas por una voz narrativa en tercera persona de la misma manera que la estrategia del silencio esgrimida contra Luis, y es silenciada porque representa el silencio de la subordinación de la mujer al orden patriarcal. El relato, pues, representa una sociedad patriarcal que no permite a la mujer expresarse libremente para llegar a ser un individuo completo y satisfecho; por eso, la protagonista queda confinada en un mundo cerrado hasta que percibe su propia alienación con ayuda del mundo vegetal y natural. El triunfo final de la protagonista es el de su transformación de un ser sumiso y dócil a una heroína que se hace consciente de su propio desencanto, y, una vez derribado el árbol, adquiere autonomía propia y se libera del orden patriarcal.

\section{OBRAS CITADAS}

Agosín, Marjorie. Las desterradas del paraíso, protagonistas en la narrativa de María Luisa Bombal. New York: Senda Nueva de Ediciones, 1983. . "Espacio y lenguaje feminocéntrico en tres obras de María Luisa

Bombal". Dinámica y dimensiones de su literatura. A Symposium. Upper Montclair, NJ: Montclair State Coll., 1985.

Bente, Thomas O. "María Luisa Bombal's Heroines: Poetic Neuroses and Artistic Symbolism”. Hispanófila 28 (1984-85): 103-113.

Bigwood, Carol. Earth Muse. Feminism, Nature, and Art. Philadelphia:Temple UP, 1993. Bombal, María Luisa. "El árbol". Cuento hispanoamericano. Ed. Seymour Menton. México: Fondo de Cultura Económica, 1986.

A., 1990.

Borinsky, Alicia. "El paisaje de la apatía". María Luisa Bombal: Apreciaciones críticas. Ed. Marjorie Agosín, Elena Gascón-Vera y Joy Renjilian-Burgy. Tempe: Bilingual Press/Editorial Press, 1987: 31-42.

Cárdenas, Daniel. "María Luisa Bombal - 'El árbol"”. Kañina 4 (1980): 55-9.

Daly, Mary. Beyond God the Father. Toward a Philosophy of Women's Liberation. Boston: Beacon Press, 1973.

Debicki, Andrew. "Structure, Imagery and Experience in María Luisa Bombal's 'The Tree"”. Studies in Short Fiction 8 (1971): 123-29.

Díaz, Gwendolyn. "Desire and Discourse in María Luisa Bombal's New Islands". Hispanófila 112 (1994): 51-63.

Dölz-Blackburn, Inés. "Elementos narrativos tradicionales en la obra de María Luisa Bombal y su relación con motivos folklóricos universales". María Luisa Bombal, Apreciaciones críticas. Ed. Marjorie Agosín, Elena Gascón-Vera y Joy RenjilianBurgy. Tempe: Bilingual Press/Editorial Press, 1987: 51-71. 
Fernández, Magali. El discurso narrativo en la obra de María Luisa Bombal. Madrid: Editorial Pliegos, 1988.

Fernández, Oscar. "El árbol' y la Hoja en Tres Cuentos: J. R. R. Tolkien, O. Henry y María Luisa Bombal”. Revista mejicana 42 (1978): 352-380.

Frye, Northrop. Anatomy of Criticism. Princeton: Princeton UP, 1957.

Gálvez Lira, Gloria. María Luisa Bombal: Realidad y fantasía. Potomac, MD: Scripta Humanística, 1986.

Genette, Gérard. Narrative Discourse: An Essay in Method. Ithaca: Cornell UP, 1980.

Guerra-Cunningham, Lucía. La narrativa de María Luisa Bombal: Una visión de la existencia femenina. Madrid: Editorial Playor, 1980.

- "Visión de lo femenino en la obra de María Luisa Bombal: Una dualidad contradictoria del ser". Revista Chilena de Literatura 25 (1985): 87-99.

Hall, Nor. The Moon and the Virgin. Reflections on the Archetypal Feminine. New York: Harper and Row, 1980.

Hamon, Philippe. Introduction à l'analyse descriptif. Paris: Classiques Hachette, 1981.

Mattelart, Michelle y Armand. La mujer chilena en la nueva sociedad. Santiago: Editorial del Pacífico, S.A., 1968.

Millet, Kate. Sexual Politics. New York: Avon Books, 1971.

Parra, Teresita. "Feminist Ideas in the Works of Clorinda Matto de Turner, Teresa de la Parra, and María Luisa Bombal". Multicultural Literatures through Feminist/ Poststructuralist Lenses. Ed. Waxman-Barbara-Frey. Knoxville: U of Tennessee P, 1993: 153-172.

Plumwood, Val. Feminism and the Mastery of Nature. London: Routledge, 1993.

Pratt, Annis. Archetypal Patterns in Women's Fiction. Bloomington: Indiana UP, 1981.

Rich, Adrienne. Of Woman Born: Motherhood as Experience and Institution. New York: W. W. Norton, 1976.

Sandler, Joseph. "Dreams, Unconscious Fantasies, and Identity of Perception". International Review of Psycho-Analysis 3 (1976): 33-41.

Scott, Nina. "Verbal and Nonverbal Message in María Luisa Bombal's 'El árbol"”. Modern Language Studies 17 (1987): 3-9.

Seymour, Menton. Editor. El cuento hispanoamericano. México: Fondo de Cultura Económica, 1986.

Sepúlveda-Pulvirenti, Emma. "María Luisa Bombal y el silencio". María Luisa Bombal, Apreciaciones críticas. Ed. Marjorie Agosín, Elena Gascón-Vera y Joy RenjilianBurgy. Tempe: Bilingual Press/Editorial Press, 1987: 230-36.

Sibbald, K. M. y Adriana Ilse Luraschi. "Bajo índice de narratividad, ambigüedad narrativa e ideología feminista en 'El árbol' de María Luisa Bombal". María Luisa Bombal, Apreciaciones críticas. Ed. Marjorie Agosín, Elena Gascón-Vera y Joy Renjilian-Burgy. Tempe: Bilingual Press/Editorial Press, 1987: 237-42.

Stacey, Jackie. "Untangling Feminist Theory". Thinking Feminist Key Concepts in Women's Studies. Diane Richardson y Victoria Robinson eds. New York: The Guilford Press, 1993: 49-73. 
In this article I analyze how María Luisa Bombal reflects the condition of the Hispanic woman through her social and historical textualization. In all of her literary work, there exists a constant presence of nature that comes to symbolize her feminine character intimacy and their marginal situation. In "The Tree", the author presents a dichotomic structure that polarizes the narrative into two antagonistic, hierarchic, and different forces. And, the barrier that delimits them constitutes a border that separates these two irreconcilable worlds.

María Luisa Bombal reveals in this short story how the patriarchal system ignores the feminine subjectiv ity, and how this one achieves expression in the alienated withdrawal of nature. 